\title{
Cinnamate-Functionalized Natural Carbohydrates as Photopatternable Gate Dielectrics for Organic
}

\section{Transistors}

Zhi Wang, ${ }^{\dagger}, \#$ Xinming Zhuang, $, \S, \#$ Yao Chen, ${ }^{\ddagger}$ Binghao Wang, ${ }^{\ddagger}$ Junsheng Yu, ${ }^{\S}$ Wei Huang, $*,+$ Tobin J. Marks, ${ }^{*}$, and Antonio Facchetti $*,+$,

${ }^{\dagger}$ Research Center for Engineering Technology of Polymeric Composites of Shanxi Province, School of Materials Science and Engineering, North University of China, Taiyuan, 030051, P. R. China

tDepartment of Chemistry and the Materials Research Center, Northwestern University, 2145 Sheridan Road, Evanston, IL 60208, USA

\$State Key Laboratory of Electronic Thin Films and Integrated Devices, School of Optoelectronic Science and Engineering, University of Electronic Science and Technology of China, Chengdu 610054, P. R. China

"Flexterra Inc., 8025 Lamon Avenue, Skokie, IL 60077, USA

\section{Synthesis of cellulose cinnamate ${ }^{1,2}$}

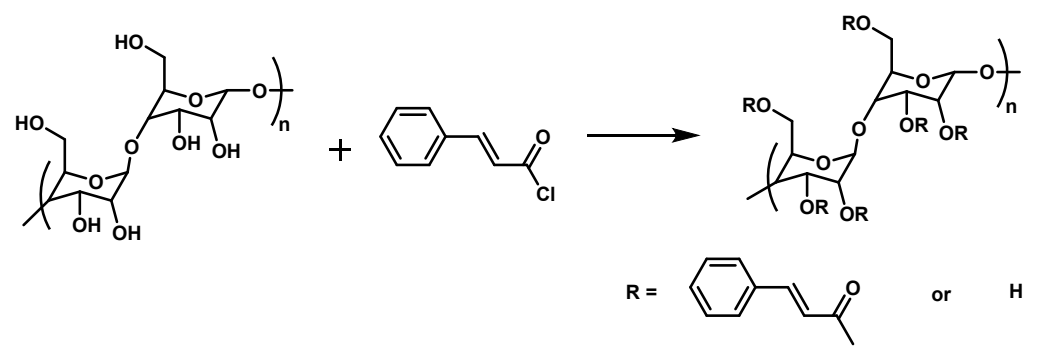

A suspension of $1.0 \mathrm{~g}(6.2 \mathrm{mmol})$ of cellulose in $40 \mathrm{~mL}$ of $\mathrm{N}, \mathrm{N}$-dimethylacetamide (DMA) was kept at $130{ }^{\circ} \mathrm{C}$ for $2 \mathrm{~h}$ under stirring. After the slurry was allowed to cool to $100{ }^{\circ} \mathrm{C}, 3 \mathrm{~g}$ of anhydrous $\mathrm{LiCl}$ was added, and the cellulose completely dissolved during the time the solution was cooled to room temperature under stirring. Next the cellulose solution was cooled an ice bath for 15 min and then $3.2 \mathrm{~g}$ (19.2 mmol) of cinnamoyl chloride was added. The reaction mixture was heated 
at $80^{\circ} \mathrm{C}$ for $24 \mathrm{~h}$. Next, the reaction mixture was poured into an excess volume of ethanol $(100 \mathrm{~mL})$ and the precipitate collected by filtration. The residue was next extracted with ethanol in a Soxhlet extractor for $12 \mathrm{~h}$ and then dried under vacuum at $50{ }^{\circ} \mathrm{C}$. Yield: $84.3 \%$. The degree of substitution of 2.55 was determined by elemental analysis). Analysis Calculated for $\left(\mathrm{C}_{33} \mathrm{H}_{29} \mathrm{O}_{8}\right)_{\mathrm{n}}: \mathrm{C}, 71.6 \% ; \mathrm{H}$, $5.28 \%$; O, 23.12\%. Found: C, 67.94\%; H, 5.36\%. FTIR (ATR mode): $1687 \mathrm{~cm}^{-1}$ (s, C=O), 3500 $\mathrm{cm}^{-1}$ (w, $\left.-\mathrm{OH}\right), 1500 \mathrm{~cm}^{-1}$ and $1600 \mathrm{~cm}^{-1}$ (s, benzene ring).

\section{Synthesis of sucrose cinnamate ${ }^{3,4}$}
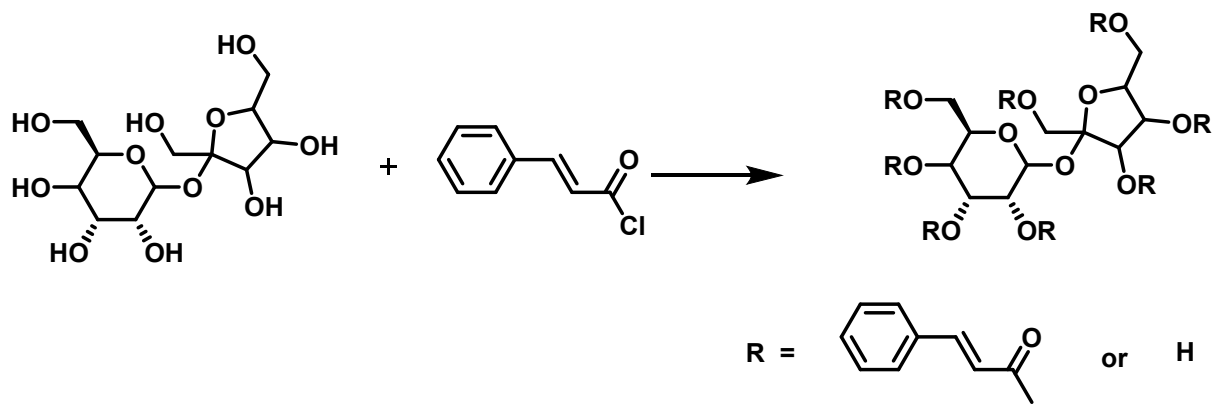

A solution of $1.71 \mathrm{~g}(5 \mathrm{mmol})$ of sucrose in $40 \mathrm{~mL}$ pyridine was placed in a three necked flask equipped with a stirrer, a reflux condenser, and a dropping funnel and stirred at room temperature for $30 \mathrm{~min}$. Then, $8 \mathrm{~g}$ (48 mmol) of cinnamoyl chloride was dissolved in $20 \mathrm{~mL}$ chloroform and added to the sucrose solution cooled in an ice bath. The system was heated at $60^{\circ} \mathrm{C}$ for $24 \mathrm{~h}$, and then absolute ethanol was added until the first sign of permanent turbidity was observed. Upon leaving the suspension at room temperature for $48 \mathrm{~h}$ a gum separated, which was taken-up with chloroform. Filtration and then slow evaporation of this solution yielded a yellow, and powdery solid. The product was further purified by two more dissolution/precipitations with from chloroform with ethanol. Yield: $80.1 \%$. Degrees of substitution is 7.92 (determined by means of elemental analysis). Analysis Calculated for $\mathrm{C}_{84} \mathrm{H}_{70} \mathrm{O}_{19}: \mathrm{C}, 72.93 \% ; \mathrm{H}, 5.10 \%$;, $21.97 \%$. Found: $\mathrm{C}, 72.75 \%$; $\mathrm{H}, 5.31 \%$. FTIR (ATR mode): $1700 \mathrm{~cm}^{-1}\left(\mathrm{~s}, \mathrm{C}=\mathrm{O}\right.$ ), $3500 \mathrm{~cm}^{-1}$ (w, $\left.-\mathrm{OH}\right), 1500 \mathrm{~cm}^{-1}$ and $1600 \mathrm{~cm}^{-}$ ${ }^{1}$ (s, benzene ring).

\section{Synthesis of glucose cinnamate ${ }^{3-5}$}

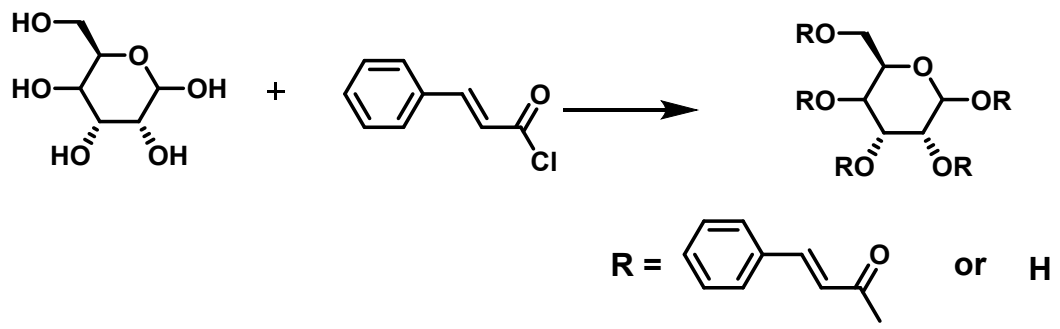

A solution of $0.9 \mathrm{~g}(5 \mathrm{mmol})$ glucose in $40 \mathrm{~mL}$ of pyridine was placed in a three necked flask equipped with a stirrer, a reflux condenser, and a dropping funnel, and stirred at room temperature. Next, $5 \mathrm{~g}$ ( $0.03 \mathrm{~mol})$ of cinnamoyl chloride dissolved in $20 \mathrm{~mL}$ chloroform was dropped into the solution cooled by an ice bath. The reaction mixture was then heated at $60{ }^{\circ} \mathrm{C}$ for $24 \mathrm{~h}$, and then absolute ethanol was added until the first sign of permanent turbidity. By leaving this suspension at room temperature for $48 \mathrm{~h}$ a gum separated, which was taken-up with chloroform. Upon slow 
evaporation of this solution a yellow, and powdery solid was obtained. The product was further purified by two more dissolution/precipitations with chloroform, then ethanol. Yield: $77.5 \%$. The degree of substitution is 4.89 (determined by means of elemental analysis). Analysis Calculated for $\mathrm{C}_{51} \mathrm{H}_{42} \mathrm{O}_{11}$ : C, 73.72\%; H, 5.10\%; O, 21.18\%. Found: C, 73.53\%; H, 5.20\%. FTIR (ATR mode): $1690 \mathrm{~cm}^{-1}$ (s, C=O), $3495 \mathrm{~cm}^{-1}$ (w, $\left.-\mathrm{OH}\right), 1500 \mathrm{~cm}^{-1}$ and $1600 \mathrm{~cm}^{-1}$ (s, benzene ring).

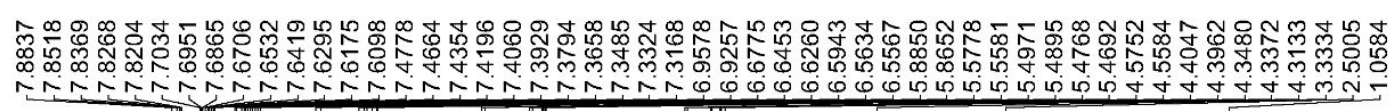

glucose cinnamate

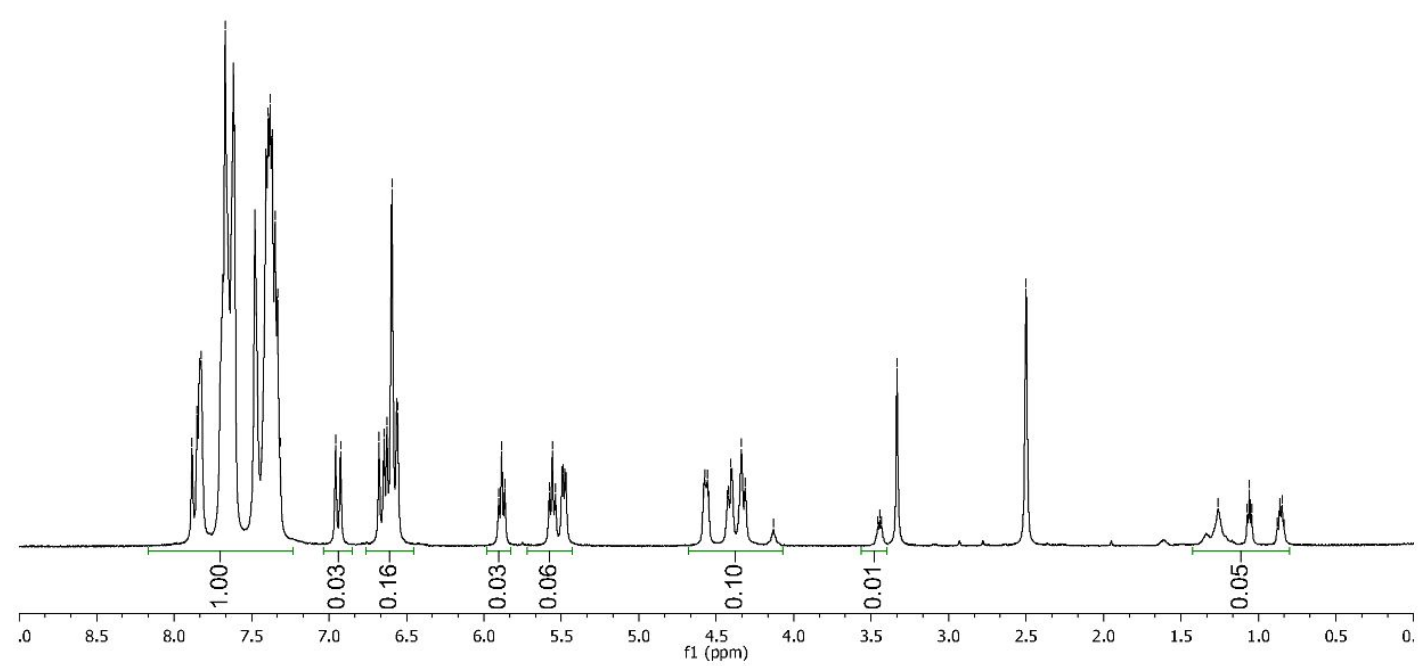

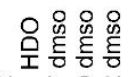

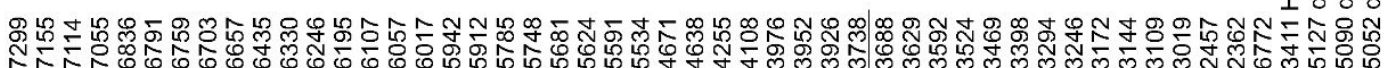

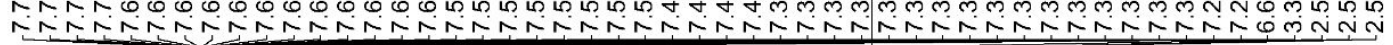

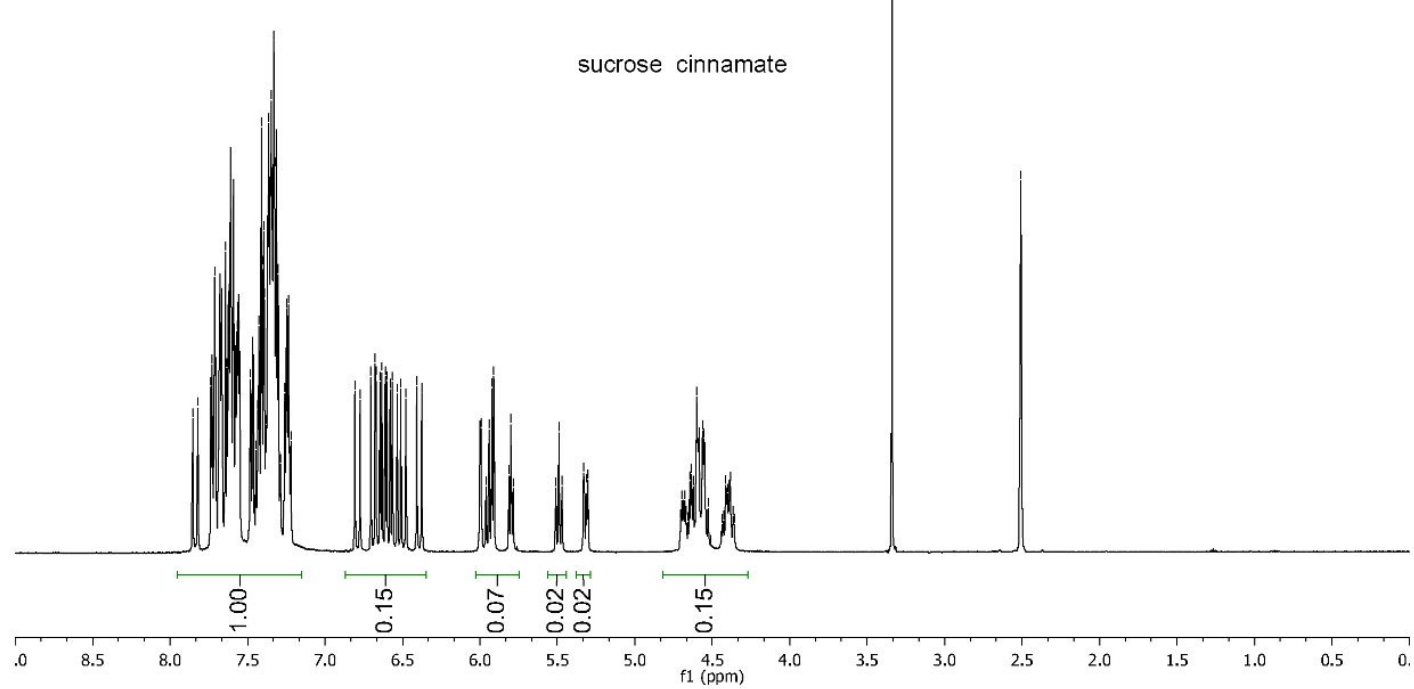




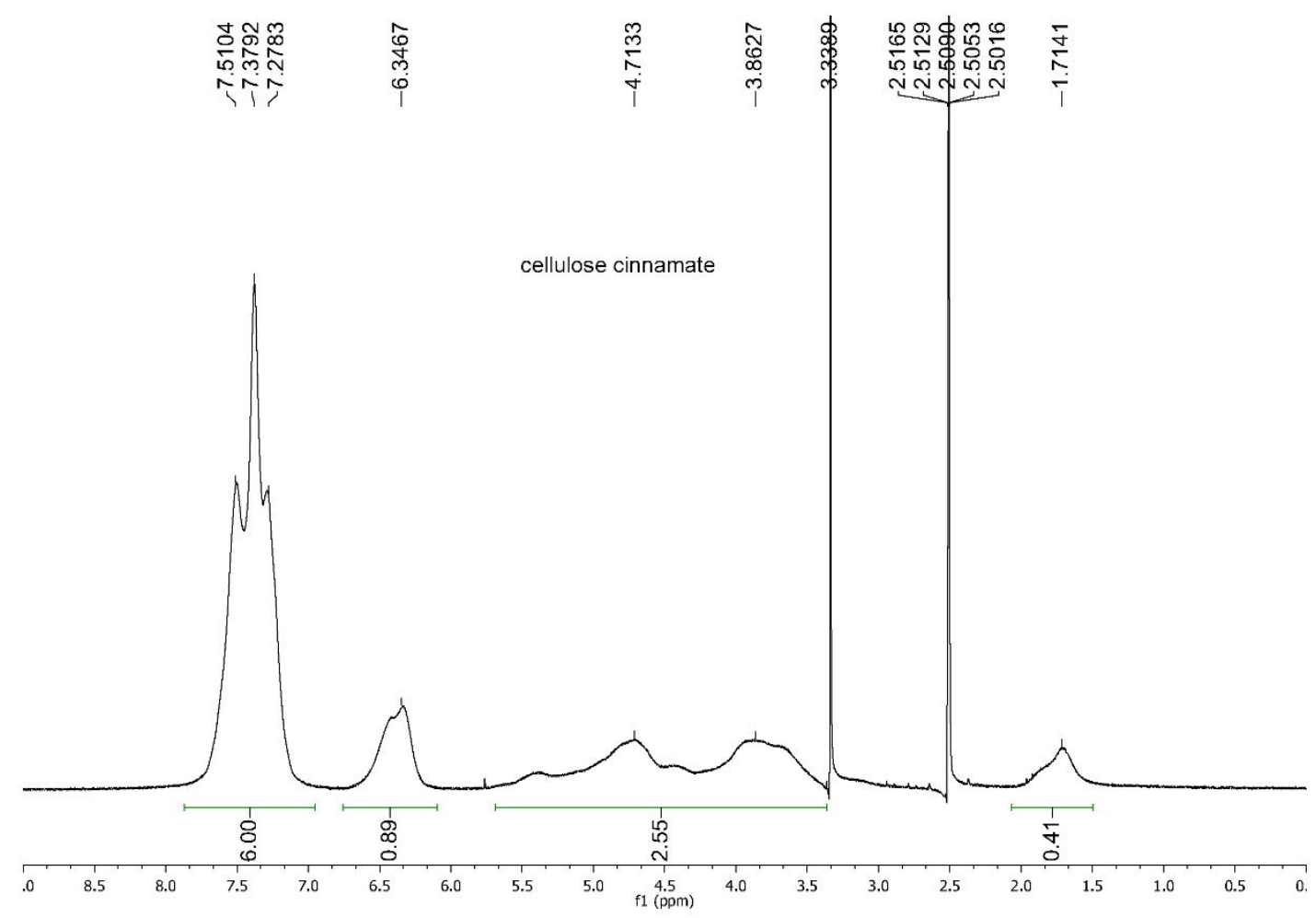

Figure S1. 1H-NMR (d6-DMSO as solvent) of glucose cinnamate, sucrose cinnamate, cellulose cinnamates.
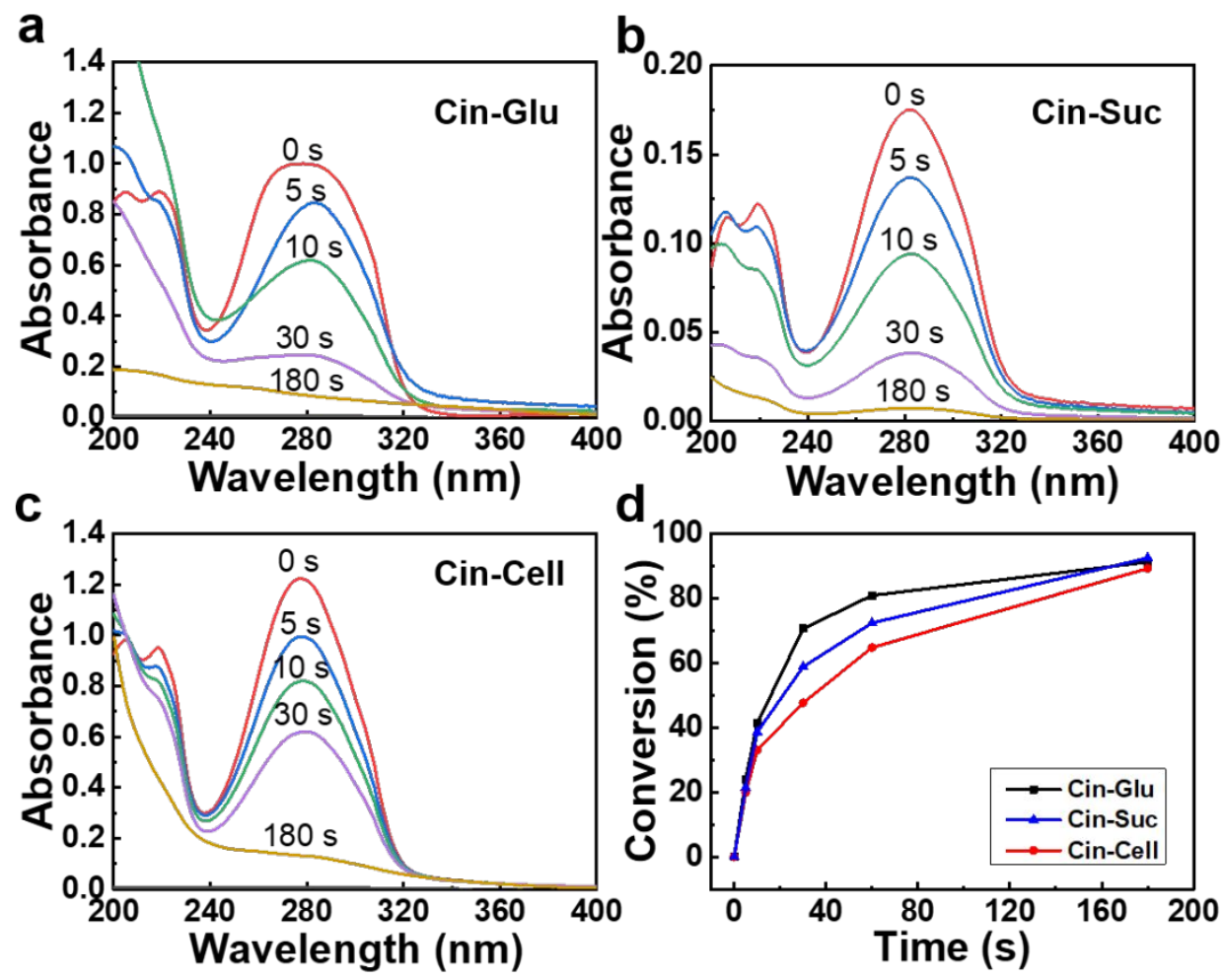

Figure S2. (a-c) UV-vis spectra of Cin-Carb films on quartz substrates as a function of the indicated UV curing times. (d) Conversion degrees vs. curing time of Cin-Carbs. 


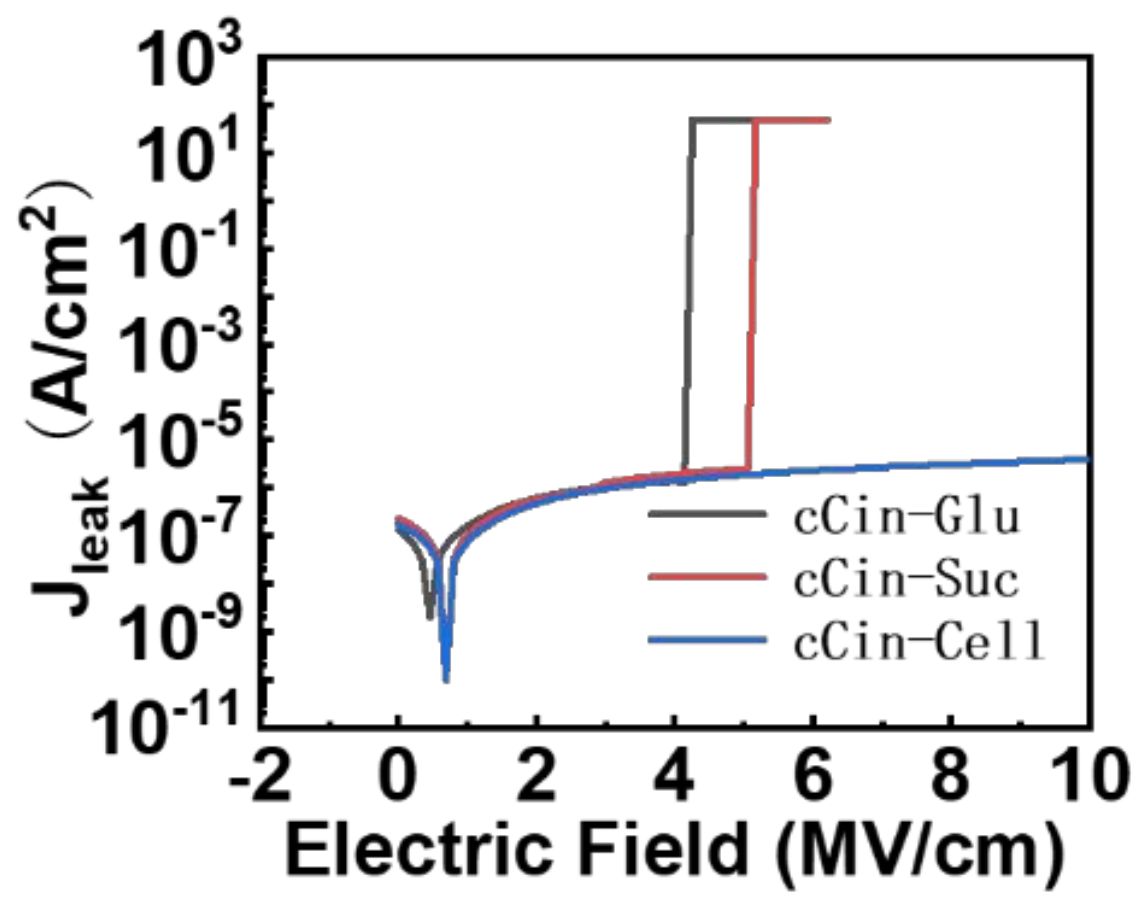

Figure S3. Dielectric breakdown characteristics of $c$ Cin-Glu, $c$ Cin-Suc, and $c$ Cin-Cell films $(\sim 100 \mathrm{~nm}$ thick) fabricated in ambient.

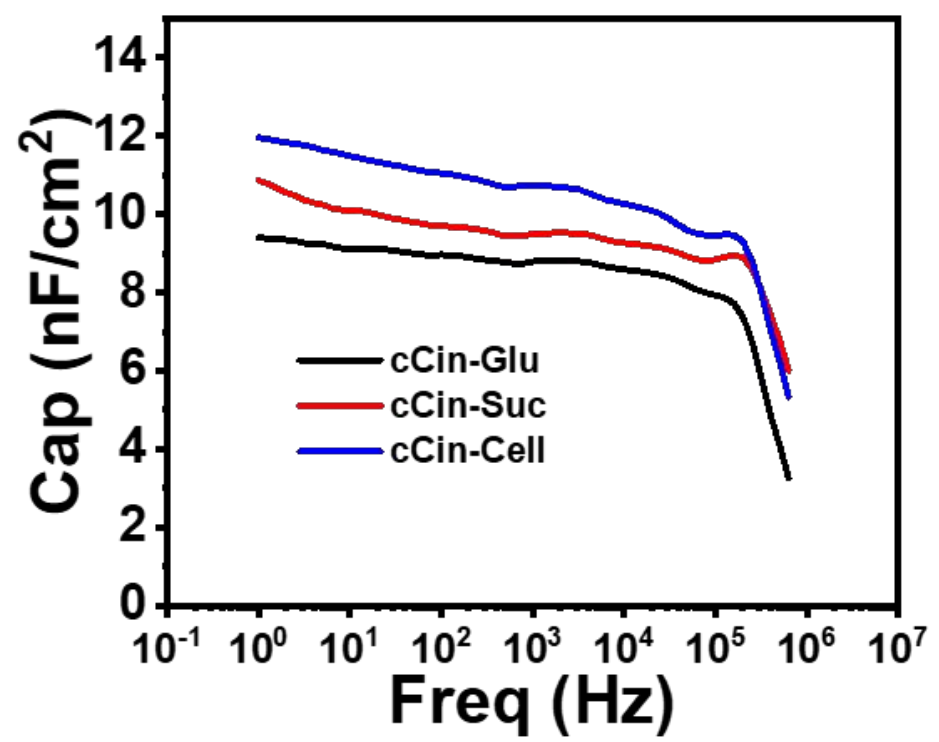

Figure S4. Capacitance-frequency plots of $c$ Cin-Glu, $c$ Cin-Suc, and $c$ Cin-Cell based capacitors. 

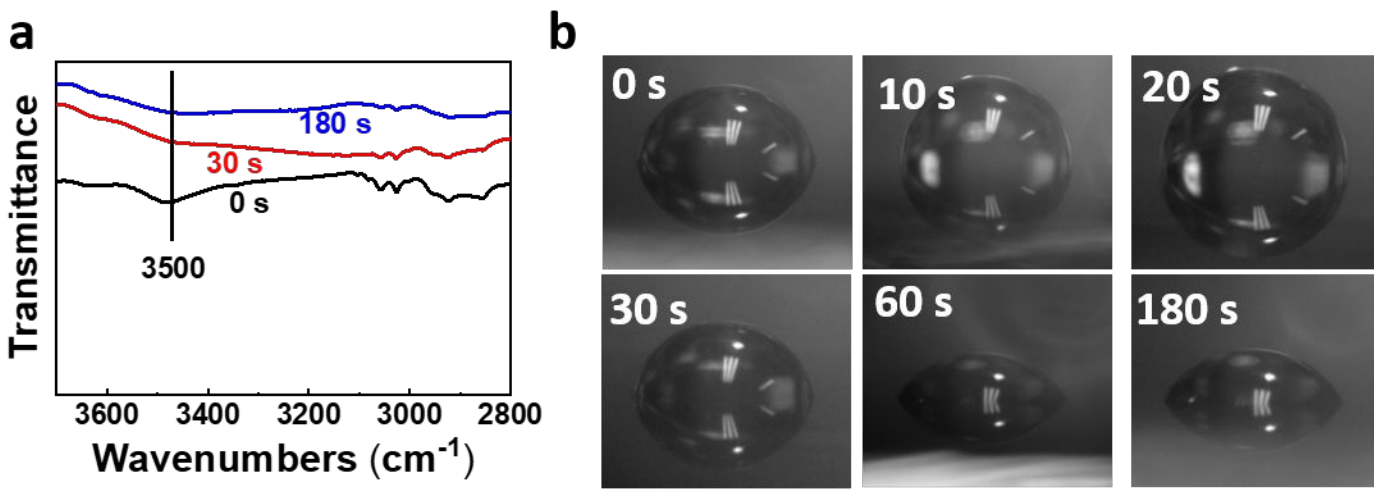

Figure S5. (a) FTIR spectrum of Cin-Cell with different UV curing times in the range of $3600 \mathrm{~cm}^{-1}-2800 \mathrm{~cm}^{-1}$. (b) Photographs of water droplets on Cin-Cell films UV cured for the indicated curing times.

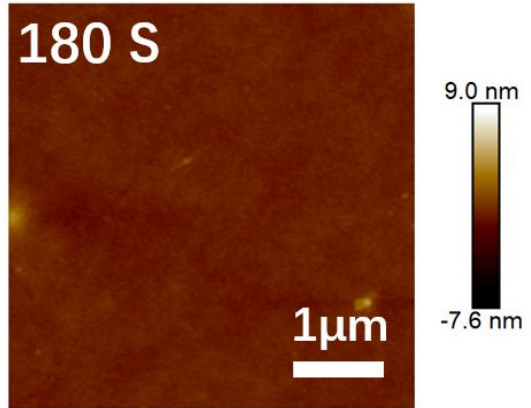

Figure S6. AFM images of a patterned Cin-Cell film UV cured for $180 \mathrm{~s}$.

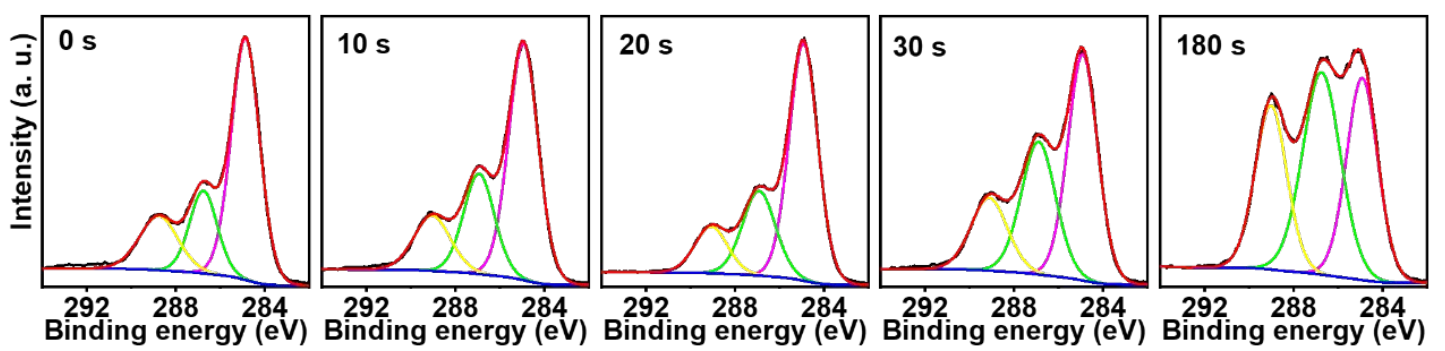

Figure S7. C1s XPS spectra of Cin-Cell films UV cured for the indicated times. Note, the surface of the films was not etched.

Table S1. XPS data of cellulose UV cured for the indicated times. Note, the amount of carbon and oxygen are derived from fitting the $\mathrm{C} 1 \mathrm{~s}$ and $\mathrm{O}$ 1s peaks.

\begin{tabular}{cccccc}
\hline $\begin{array}{c}\text { Composition } \\
\text { (atomic\%) }\end{array}$ & $\mathbf{0 ~ s}$ & $\mathbf{1 0 ~ s}$ & $\mathbf{2 0 ~ s}$ & $\mathbf{3 0 ~ s}$ & $\mathbf{1 8 0} \mathbf{~ s}$ \\
\hline Carbon & 73.0 & 71.6 & 72.1 & 67.6 & 59.3 \\
Oxygen & 27.0 & 28.5 & 27.9 & 32.4 & 40.7 \\
\hline
\end{tabular}



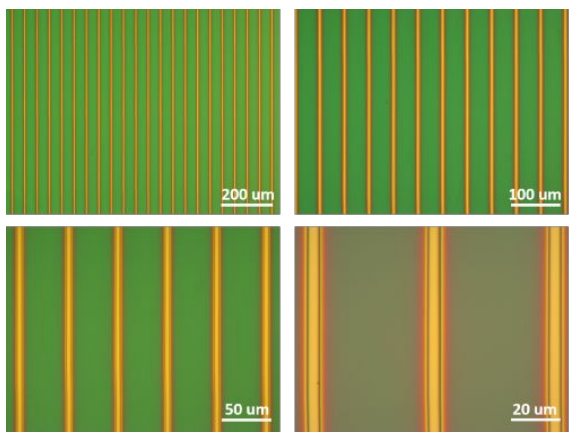

Figure S8. $c$ Cin-Cell patterned features using photolithography. Note, the green color indicates $c$ Cin-Cell and the yellow refers to the exposed Si substrate surface.
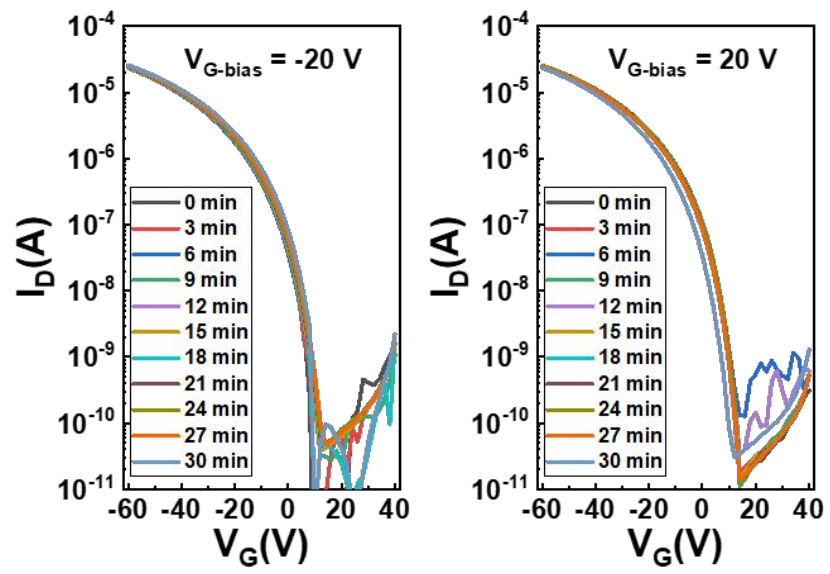

Figure S9. Bias stress of pentacene TFTs with patterned Cin-Cell dielectrics and semiconductors. Note, $c$ Cin-Cell is cured for $180 \mathrm{~s}$. The gate bias voltage is $-20 \mathrm{~V}$ or 20 $\mathrm{V}$ as indicated in the figures. 


\section{References}

1. Heinze, T.; Liebert, T. F.; Pfeiffer, K. S.; Hussain, M. A., Unconventional cellulose esters: synthesis, characterization and structure-property relations. Cellulose 2003, 10 (3), 283-296.

2. Arai, K.; Satoh, H., Liquid crystalline phase-formation behavior of cellulose cinnamate. Journal of applied polymer science 1992, 45 (3), 387-390.

3. Black, W. A. P.; Dewar, E. T.; Paterson, J. C.; Rutherford, D., Alkali metal derivatives of sucrose. II. Condensation of sodium sucrates with organic halogen compounds. Journal of Applied Chemistry 1959, 9 (5), 256-265.

4. Zief, M., Unsaturated Esters of Sucrose. Journal of the American Chemical Society 1950, 72 (3), 1137-1140.

5. Teramoto, N.; Shibata, M., Synthesis and photocuring of cinnamoyl trehalose esters. Polymers for Advanced Technologies 2007, 18 (12), 971-977. 